\title{
O MODELO DE INTERNACIONALIZAÇÃO DE UPPSALA SOB A ÓTICA DA VISÃO BASEADA EM RECURSOS (RBV)
}

\author{
Ana Paula Pydd Teixeira, Mestre em Administração - Unisinos, Francisco Sperotto Flores, Mestrando em \\ Administração - Unisinos \\ anaredesociais@gmail.com, chico041986@gmail.com
}

\begin{abstract}
RESUMO
A escola de Uppsala propõe um modelo que considera o aumento gradual do nível de internacionalização das empresas, que ocorre através da obtenção de conhecimento sobre novos mercados e o comprometimento de recursos. Mudanças no ambiente de negócios e releituras teóricas levaram ao reconhecimento da influência das redes de negócio sobre os processos de aprendizagem e obtenção de conhecimento das empresas que se internacionalizam. Este estudo ambiciona revisitar o modelo de Uppsala sob a ótica de visão baseada em recursos (RBV). Através de revisão teórica, analisam-se os pontos comuns entre as duas abordagens e suas complementaridades. Desta forma, discute-se o papel dos recursos e sua importância para a geração de conhecimento e aprendizagem das empresas durante processos de internacionalização.

Palavras-chave: Uppsala, Internacionalização, Visão Baseada em Recursos (RBV).

\section{THE UPPSALA INTERNACIONALISATION MODEL UNDER THE RESOURCE BASED VIEW (RBV) PERSPECTIVE}

\begin{abstract}
The school of Uppsala proposes a model that considers the gradual increase in the level of internationalization, which would by obtaining knowledge about new markets and the commitment of resources. Changes in the business environment and theoretical readings led to the recognition of the influence of business networks on the processes of learning and obtaining knowledge of the companies that internationalize. This study aims to revisit the Uppsala model from the perspective of resource-based ( $R B V)$. Through literature review, we analyze the commonalities between the two approaches and their complementarities. Thus, we intend to discuss the role of resources and their importance to the generation of knowledge and learning of the companies during the internationalization process.
\end{abstract}

Keywords: Uppsala, Internationalization, Resource Based View (RBV).

\section{Introdução}

Estudos sobre o processo de internacionalização de empresas suecas realizados por pesquisadores da Universidade de Uppsala observaram que estas empresas seguiam um padrão gradual de internacionalização de suas operações. A partir destas pesquisas, desenvolveu-se um modelo baseado em um processo gradual resultante da interação entre aprendizagem e comprometimento de recursos. A escola de Uppsala sugere que as empresas iniciam sua expansão internacional através de pequenos investimentos em mercados culturalmente próximos, e, a partir da aprendizagem e da obtenção de conhecimento sobre estes mercados, ampliam seus investimentos, expandindo suas operações para mercados culturalmente mais distantes. Assim, o modelo de Uppsala tende a privilegiar o aspecto comportamental e o crescimento da firma, 
através do aumento gradual do nível de internacionalização a partir da obtenção de conhecimento sobre novos mercados e do comprometimento de recursos das empresas nestes novos mercados (JOHANSON e VAHLNE, 1977).

Diversos estudos foram realizados a fim de analisar o padrão de internacionalização e entender como ocorre o aprendizado das organizações e como este processo de aprendizagem afeta o comprometimento das empresas com o mercado (JOHANSON e WIEDERSHEIMPAUL, 1975; JOHANSON e VAHLNE, 1977; 2010; SCHWEIZER; VAHLNE e JOHANSON 2010). Paradoxalmente, outros autores apresentaram críticas e evidências contrárias ao modelo (MILLINGTON e BAYLISS, 1990; JARILLO e MARTINEZ, 1991; MELIN, 1992; ANDERSEN, 1993; HEMAIS e HILAL, 2002; WHITELOCK, 2002; GÓES e ROCHA, 2007).

A partir das mudanças no ambiente de negócios internacionais e dos avanços teóricos decorrentes, os autores propuseram ajustes ao modelo original de Uppsala, incorporando, por exemplo, o conceito de redes ao processo de internacionalização (JOHANSON e VAHLNE, 2010; SCHWEIZER, VAHLNE e JOHANSON, 2010). Influenciados por Penrose (1966) e a Visão Baseada em Recursos (RBV), o modelo de Uppsala passou a assumir que os recursos disponíveis são heterogêneos e que, independentemente das condições de mercado, conduzem à criação de valor.

Este estudo busca analisar o modelo de Uppsala e suas vertentes, a partir da ótica da visão baseada em recursos (RBV). Utiliza-se revisão teórica a fim de perscrutar as duas abordagens. Para tanto, o artigo divide-se em quatro seções: a primeira seção faz uma revisão conceitual da escola de Uppsala, a segunda revisita a Visão Baseada em Recursos (RBV), a terceira procura discorrer sobre o encontro observável entre os dois modelos teóricos e suas decorrentes complementaridades. Por fim, apresentam-se, na última seção, as considerações finais, implicações e sugestões para futuros estudos.

\section{O modelo de UPPSALA}

A partir da observação do processo de internacionalização de quatro empresas suecas, Johanson e Wiedersheim-Paul (1975) identificaram que essas empresas se internacionalizavam com poucos investimentos e gradualmente tendiam a aumentar sua presença no exterior. Em um primeiro momento, as empresas realizavam vendas diretas para um novo mercado, sem comprometimento de recursos. Em uma segunda etapa, passavam a exportar através de um agente. O terceiro passo consistia na criação de uma subsidiária de vendas, seguida pela produção no novo mercado, o que já representava um grande comprometimento de recursos.

A escolha dos primeiros mercados estava relacionada à distância psíquica entre o país de origem e o país importador, entendida como a "soma dos fatores que interferiam no fluxo de informação entre paises" (JOHANSON e VAHLNE, 1977, p. 24). Assim, firmas com pouca experiência em mercados estrangeiros preferiam iniciar sua internacionalização em mercados com características semelhantes ao seu mercado doméstico, ou seja, culturalmente mais próximas. (ERIKSSON et al., 1997).

A escola de Uppsala propôs um modelo de internacionalização com foco no comportamento e crescimento da firma através do aumento gradual do nível de internacionalização da empresa, que ocorria a partir da obtenção de conhecimento sobre novos mercados e comprometimento de recursos nestes novos mercados (JOHANSON e VAHLNE, 1977).

Buscando explicar a interação entre a obtenção de conhecimento e o comprometimento de recursos nos novos mercados, os autores analisaram as variáveis do processo de internacionalização a partir de aspectos de estado e mudança. Os aspectos de estado envolviam o comprometimento de recursos nos novos mercados e o conhecimento obtido nas operações no mercado estrangeiro. Já os aspectos de mudança representavam as decisões de alocação de recursos e o desempenho dos negócios da empresa. 
O comprometimento de recursos leva em consideração o volume de recursos investidos em um mercado e o grau de comprometimento destes na operação. Quanto mais integrados ou dependentes os recursos operacionais, maior o comprometimento da firma com o mercado. As decisões de comprometimento são baseadas em conhecimento. A avaliação das alternativas de alocação é baseada no conhecimento sobre os mercados e no desempenho das atividades das empresas. Ao desenvolverem o conceito, os autores consideram o conhecimento como fruto da experiência, podendo ser obtido apenas através de experiência aplicada, ou seja, na prática corrente das empresas.

As atividades seriam a primeira fonte de experiência. Esta experiência seria obtida diretamente pela firma a partir da operação e dos desdobramentos do mercado. No entanto, esta também podia ser obtida através da contratação de pessoas com conhecimento do contexto em questão ou através de aconselhamento com profissionais detentores de experiências em negócios internacionais. Já as decisões de comprometimento eram vistas como respostas a problemas ou oportunidades do mercado, que surgiriam de acordo com o crescimento da firma. Seriam, portanto, dependentes das alternativas disponíveis e da identificação de problemas ou oportunidades (JOHANSON e VAHLNE, 1977).

A desconsideração de aspectos que podem afetar o processo de internacionalização, como características do produto, da indústria e do mercado, a concorrência e fatores estratégicos (MELIN, 1992; WHITELOCK, 2002; GÓES e ROCHA, 2007), assim como seu caráter determinista (ANDERSEN, 1993; HEMAIS e HILAL, 2002), que não explicaria a internacionalização de boa parte das empresas (JARILLO e MARTINEZ, 1991, MILLINGTON e BAYLISS, 1990; HEMAIS e HILAL, 2002), ignorando ocasiões onde o processo de internacionalização não se daria de forma gradual (MCDOUGALL, SHANE, e OVIATT, 1994), gerou uma série de críticas ao modelo de Uppsala. Em resposta às criticas e apoiados em evidências empíricas, tais como o papel desempenhado pelas redes de relacionamento durante o processo de internacionalização, os autores propuseram ajustes ao modelo, incorporando, posteriormente, o conceito de redes (JOHANSON e VAHLNE, 2009).

A visão de redes sugere que o processo de internacionalização não depende apenas dos recursos da firma, mas também sofre influência da rede de relações nas quais se inserem as empresas, que propicia condições para o aprendizado, para a construção de confiança e comprometimento (JOHANSON e VAHLNE, 2009). Dentro da rede de negócio, as empresas deixam de aprender apenas a partir das suas próprias experiências, passando a obter e desenvolver conhecimento ao interagir com outras empresas. Desta forma, o modelo de Uppsala se modifica, alterando as variáveis relacionadas às condições e mudanças (Figura 1).

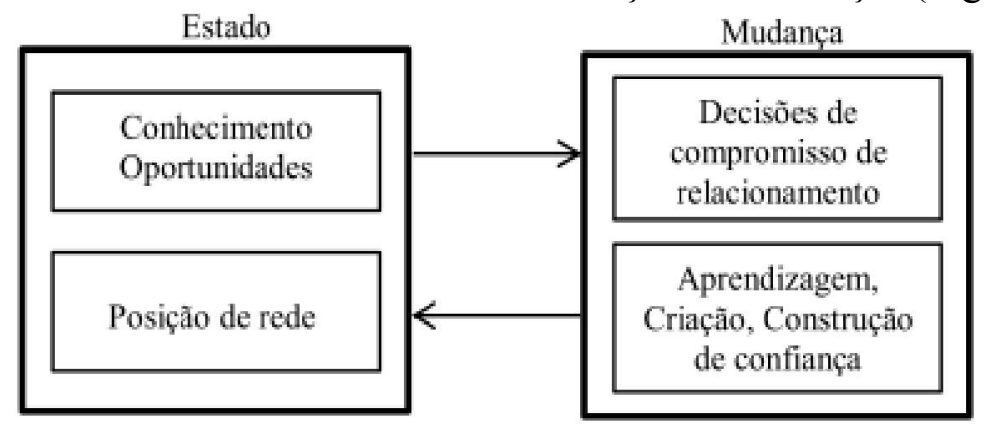

Figura 1: O Modelo de Rede de Negócios do Processo de Internacionalização (JOHANSON e VAHLNE, 2009)

Quanto aos aspectos de estado, emergem no novo modelo as noções de necessidade, capacidade e estratégia como relevantes para a obtenção de conhecimento, além do conceito de oportunidades, que reconhece a identificação das mesmas como o elemento mais importante para a geração de conhecimento. $\mathrm{O}$ comprometimento com o mercado passa a ser visto como posição 
de rede, o que permite entender que o relacionamento é caracterizado por níveis específicos de conhecimento, confiança e comprometimento entre as partes envolvidas e que estas podem adotar estratégias distintas durante o processo de internacionalização. (JOHANSON e VAHLNE, 2009).

Nas variáveis de mudança, as decisões de comprometimento passam a ser definidas como decisões de compromisso de relacionamento, o que revela que as decisões de comprometimento envolvem relacionamentos e redes de negócios. Por fim, o conceito de atividades atuais passa a abarcar a aprendizagem, criação e construção de confiança, levando a uma maior ênfase no resultado destas atividades (JOHANSON e VAHLNE, 2009).

Em trabalho posterior, Schweizer, Vahlne e Johanson (2010) descrevem a internacionalização como resultante dos esforços para fortalecer a posição de uma empresa dentro da rede de negócios, fruto da ação empreendedora da firma. Os autores acrescentam o elemento empreendedor ao modelo. (Figura 2).

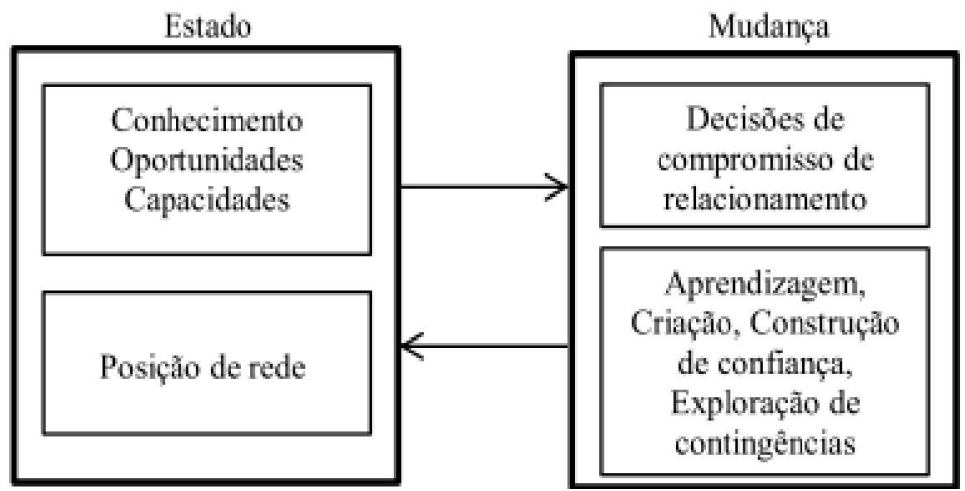

Figura 2: Internacionalização como processo empreendedor (SCHWEIZER,VAHLNE e JOHANSON, 2010)

Este novo modelo passa a reconhecer que a aprendizagem experiencial é essencial (JOHANSON e VAHLNE,1977; 2009; SCHWEIZER, VAHLNE e JOHANSON, 2010), e que o empreendedor que consegue viver sob um ambiente de incerteza e ambigüidade que envolva aprendizagem possui uma vantagem (SCHWEIZER, VAHLNE e JOHANSON,2010). Assim, os autores incluem a capacidade empreendedora como uma variável de estado, já que esta capacidade pode auxiliar a empresa a reconhecer oportunidades e gerar conhecimento. Outro aspecto relevante diz respeito à exploração de contingências como a habilidade para construir e manter relações importantes e fazer uso destas relações, visto como uma parte importante da capacidade de aprender e criar conhecimento (SCHWEIZER, VAHLNE e JOHANSON, 2010).

\section{A visão baseada em recursos (RBV)}

A Resource Based View (RBV) ou Visão Baseada em Recursos propõe que as empresas devem empregar recursos subutilizados em novos mercados ou outras empresas com o objetivo de obter economias de escopo e sustentar vantagens competitivas (BARNEY, 1991; PRAHALAD e HAMEL, 1990). Assim, a vantagem competitiva é resultado do conjunto de recursos e capacidades empresariais, que, articulados, constituem as competências essenciais das empresas (PRAHALAD e HAMEL, 1990). Entretanto, a simples posse desse conjunto de recursos e capacidades não confere automaticamente vantagem competitiva às firmas (WERNERFELT, 1984). Esta vantagem dependerá da capacidade das empresas em identificar e utilizar racionalmente recursos valiosos, raros, difíceis de imitar e sem substitutos próximos (BARNEY, 1991). As competências essenciais, como conceito, evoluíram graças à Visão Baseada em Recursos, visto que esta explica porque algumas organizações são consistentemente melhores 
que outras em alguns mercados com recursos similares. (MAZON, DA SILVA e VIEIRA, 2009).

Desta forma, pode-se considerar que os impulsionadores da estratégia de internacionalização são os recursos exclusivos da firma e sua capacidade organizacional (ROCHA; ALMEIDA, 2006). Empresas com disponibilidade de recursos valiosos, raros, difíceis de imitar e sem substitutos próximos, terão uma vantagem sobre seus concorrentes nos mercados interno e externo (BARNEY, 1991; TREVINO e GROSSE, 2002; WESTHEAD, WRIGHT, e UCBASARAN, 2001).

Lei e Chen (2011) consideram que, devido aos desafios enfrentados nos mercados estrangeiros, as firmas devem buscar desenvolver seus recursos e capacidades como forma de superar essas adversidades. Trevino e Grosse (2002) propõem que a intensificação da concorrência global resultou em uma ênfase na inovação como meio de desenvolver e manter vantagens competitivas para as empresas. Desta forma, o processo de internacionalização é resultado não apenas da exploração de vantagens existentes, mas também da busca por novas vantagens competitivas em novos mercados (PENG, 2001).

Analisando as formas de entrada de uma empresa em um novo país sob uma perspectiva da RBV, Sharma e Erramilli (2004) argumentam que empresas com pouca probabilidade de obter vantagens competitivas em atividades de produção e comercialização em um novo mercado tendem a optar por entrar nesse mercado via exportações. Rocha e Almeida (2006) salientam que, para que recursos e capacidades possam se revelar uma vantagem competitiva devem permanecer exclusivos. Assim, as empresas tendem a evitar modos de entrada em mercados estrangeiros que se baseiem em associações e parcerias, preferindo acessos com um maior nível de controle, buscando (1) retardar o acesso de concorrentes potenciais aos recursos exclusivos da firma e (2) reduzir custos associados à transferência de informações (TREVINO e GROSSE, 2002).

Collis (1994) destaca que, embora as capacidades organizacionais, como recursos, possam levar a vantagens competitivas, existem limites para o grau de importância destes recursos, que poderiam apresentar-se mais vulneráveis a substituições e desgastes. Esta constatação leva a concluir que não existiria, a princípio, uma forma única e mais adequada para obter vantagens competitivas.

Em suma, quais contribuições da RBV apresentam-se como relevantes para explicar a internacionalização? Salazar et al (2012) contribuem, apontando alguns aspectos principais: a dinâmica dos modos de entrada em países hospedeiros, a performance das empresas internacionais, o papel dos recursos tangíveis e intangíveis da empresa e do país hospedeiro na construção da vantagem competitiva sustentável, o desenvolvimento de capacidades no processo de internacionalização e o empreendedorismo internacional.

\section{Uppsala e rbv: o encontro teórico}

Carneiro e Dib (2008) propõem uma divisão de perspectivas das teorias de internacionalização: $\S$ Abordagens baseadas em critérios econômicos: Neste grupo, encontram-se as teorias orientadas para decisões pseudo racionais, ou seja, focadas em um caminho que privilegie a maximização dos retornos econômicos;

$\S$ Abordagens calcadas na evolução comportamental: Referem-se aos processos dependentes das atitudes, percepções e comportamentos dos tomadores de decisão, que estariam orientados para reduzir os riscos das decisões de onde e como expandir.

Partindo da mesma vertente ontológica, que procura olhar a firma de dentro para fora (insideout), Uppsala e RBV seriam consideradas abordagens de evolução comportamental, pois dependem estritamente da racionalidade dos gestores no momento da tomada da decisão de internacionalizar em todas as suas etapas (SALAZAR et al., 2012). 
O surgimento da linha de pensamento comportamental abriu caminho para que os estudos de negócios internacionais pudessem deixar de ser vistos somente como fenômenos puramente econômicos e passassem a ser examinados sob a ótica do comportamento organizacional. A partir de então, a firma internacional é interpretada como uma organização formada por processos cumulativos de aprendizagem, que apresenta uma complexa teia de recursos, competências e influências. (HEMAIS e HILAL, 2002).

Ponto inegável de encontro entre as abordagens de Uppsala e a RBV diz respeito à importância dos recursos da firma. Como recursos, as competências atuam de maneira relevante para o processo de internacionalização. As competências dinâmicas destacadas por Teece, Pisano e Shuen (1997) podem ser atribuídas às forças locais ou regionais que irão contribuir para formação das capacidades das empresas em estágios iniciais. Os autores destacam que se observam diferenças mesmo entre populações de empresas de um mesmo país, o que torna estratégica a capacidade de adequar os recursos, tornando-os aplicáveis a novos ambientes. Diferentes abordagens são necessárias à aprendizagem, a depender da profundidade do conhecimento. Onde o conhecimento é menos articulado, pode ser preciso aprender com a prática, enquanto em ambientes maduros, as organizações poderiam empreender através de abordagens mais dedutivas. O desenvolvimento de capacidades dinâmicas de características globais que permitam a adequação das estratégias e configuração de recursos levaria a uma maior competitividade.

Paralelamente, pela ótica de Uppsala, a incerteza em relação ao resultado de uma ação aumenta com a distância. Supõe-se que as firmas teriam melhor conhecimento de seus ambientes mais imediatos. Desta forma, estas buscariam alternativas para sentirem-se menos "estrangeiras". (HEMAIS e HILAL, 2003). Percebe-se, também, que as empresas desenvolvem competências internacionais à medida que o grau de internacionalização aumenta, possibilitando às empresas internacionalizadas a renovação da vantagem competitiva e a sustentação do processo de internacionalização. (FLORIANI e FLEURY, 2012).

Os desafios de Uppsala estão relacionados, por exemplo, ao conhecimento e aprendizagem que exigiriam das organizações competências específicas: competências de negócio, competências técnico-profissionais, competências sociais, competências atitudinais e competências relacionadas à gestão do tempo. Para Uppsala, o comprometimento da empresa aumenta à medida que o conhecimento cresce. O comprometimento é, portanto, medido de acordo com a quantidade de recursos investidos e cresce em função direta da experiência acumulada. Assim, a percepção do risco diminui e o envolvimento tende a crescer. (SALVADOR, PORTO e PESSOA, 2009).

As empresas criam relacionamentos de forma interligada, aproveitando conexões atuais para abrir espaço a novas parcerias de negócio. A criação de conhecimento não é um processo separado das outras atividades, ao contrário, está presente em todas estas outras atividades. Desta forma, as firmas tendem a acumular conhecimento não apenas através de suas próprias ações, mas das ações das empresas parceiras. Tendo em vista que estas empresas também estabelecerão relacionamentos, o processo de criação de conhecimento irá se estender de forma muito mais ampla. Em conclusão, uma rede de negócios acabará por propiciar uma sólida base de conhecimento. Semelhantemente, para a RBV, os recursos são heterogêneos e podem conduzir à criação de valor pelas empresas, independente das condições externas ou de mercado. (JOHANSON e VAHLNE, 2009).

No entanto, a abordagem das redes integrada à visão da RBV parece fazer mais sentido em redes de cadeias globais que estejam integradas de maneira vertical, onde se observa a tendência de compartilhar os recursos entre firmas. Os participantes deste tipo de rede devem se comprometer de forma relevante com a manutenção e desenvolvimento de recursos de caráter intangível. Empresas pertencentes a cadeias globais têm a necessidade de fortalecer relações de confiança e comprometimento. (LEITE e PRIMO, 2014). 
Sob o enfoque das redes de negócio, as empresas são definidas e concebidas em torno do intercâmbio de recursos e conhecimento e não a partir de sua produção. Assim, o ambiente de negócios não se mostra estático, mas dinâmico. A incerteza recai sobre a condição de estar fora desta rede (outsidership) e não sobre a distância psíquica. No entanto, cabe ressaltar que o fato das empresas se organizarem em rede não necessariamente irá eliminar a importância da distância psíquica, pois ainda poderá se observar maior dificuldade em estabelecer relacionamentos quando esta distância for mais significativa. (SOARES, 2013).

Ser membro da rede (insidership) pode se mostrar relevante, ainda que não suficiente, para o processo de internacionalização, em razão dos relacionamentos estruturados dentro das redes possibilitarem aprendizado e construção de confiança, atributos importantes para que as empresas se internacionalizem. (CARVALHO e DIB, 2013).

Em um ambiente empresarial marcado pela evolução tecnológica acelerada, pela expansão dos sistemas de informação, comunicação e abertura dos mercados, as empresas se encontram obrigadas a repensar a forma de conduzir suas estratégias. A necessidade de sobrevivência as leva a tentar, a todo custo, extrair proveito das condições que se apresentam a fim de preservarem sua posição no mercado. As "Born Globals" são empresas que iniciam sua internacionalização não de forma gradual, mas arriscando grande parte de seus recursos. Empresas com estas características podem não contar com grande aporte de recursos financeiros ou humanos, recursos tangíveis de forma geral, no entanto, utilizam-se de um conjunto de recursos intangíveis a fim de obterem vantagem competitiva global. (REYNOSO e FIGUEROA, 2010).

As empresas brasileiras, em sua maioria, estão apenas iniciando sua atuação no contexto global. No entanto, juntamente com empresas do BRICS (Brasil, Rússia, índia, China e África do $\mathrm{Sul}$ ), começam a dar os primeiros passos em direção a uma maior internacionalização. Uma razão para o atraso no processo de internacionalização diz respeito à diferença em relação ao contexto institucional no qual se desenvolveram as empresas dos países subdesenvolvidos, como o Brasil. Hoje, o panorama nestes países se apresenta mais imprevisível, o que pode ser interpretado, por um lado, como uma ameaça a estas empresas. Por outro lado, no contexto da economia global, estes entraves se apresentam como fatores que propiciam a busca de oportunidades e flexibilidade em relação às adversidades. (CHIAVEGATTI e TUROLLA, 2011).

A partir da ótica das competências como recursos, a escola de Uppsala poderia ser analisada como fortemente dependente das competências essenciais, conforme apresentado na Tabela 1.

\begin{tabular}{|l|l|}
\hline Modelo de Uppsala & Competências \\
\hline \multirow{2}{*}{$\begin{array}{l}\text { Conhecimento: importante } \\
\text { para realização dos negócios } \\
\text { internacionais. }\end{array}$} & $\begin{array}{l}\text { Competências de negócio: compreender o negócio, seus objetivos na } \\
\text { relação com o mercado, clientes e competidores, assim como com o } \\
\text { ambiente político e social (conhecimento do negócio, orientação para o } \\
\text { cliente), maximizar a atividade inovadora baseada em conhecimentos e } \\
\text { habilidades, utilizando recursos locais de cada uma de suas unidades, que } \\
\text { possam ser usados não só localmente, mas em todos os mercados onde ela } \\
\text { opera, antecipação às demandas do ambiente competitivo. Competências } \\
\text { técnico-profissionais: competências específicas para certa operação, } \\
\text { ocupação ou atividade. (conhecimento do produto, finanças). }\end{array}$ \\
\hline $\begin{array}{l}\text { A aprendizagem é vista como um grande diferencial e estratégia } \\
\text { competitiva. A disponibilidade para aprender e ensinar são essenciais } \\
\text { assim como a cooperação. Fluxo contínuo do conhecimento bem como } \\
\text { aprendizagem. } \\
\text { seu compartilhamento, é necessário que o conhecimento seja codificado e } \\
\text { compartilhado para que não exista somente na mente das pessoas, } \\
\text { cabendo às organizações administrá-lo de forma inteligente, transferindo- } \\
\text { o através de processos de socialização, know-how coletivo. }\end{array}$
\end{tabular}




\begin{tabular}{|l|l|}
\hline $\begin{array}{l}\text { Gradualismo e } \\
\text { incrementalismo. }\end{array}$ & $\begin{array}{l}\text { Referem-se às competências relacionadas à gestão do tempo e } \\
\text { conhecimento do processo como um todo. Para a realização da } \\
\text { internacionalização é necessário seguir determinadas etapas e } \\
\text { procedimentos. }\end{array}$ \\
\hline \multirow{5}{*}{$\begin{array}{l}\text { Relacionado ao grau de investimento na internacionalização. Está } \\
\text { relacionado à um feeling de negócios e ao incentivo ao empreendedorismo } \\
\text { interno. absorvendo informações, transformando-as em } \\
\text { conhecimento,para em seguida combiná-los com suas experiências } \\
\text { anteriores, em um contexto delineado por sua cultura organizacional, } \\
\text { gerando as estratégias que necessita para obter sucesso. }\end{array}$} \\
\hline Competências sociais: competências necessárias para interagir com as \\
pessoas, conhecer realidades culturais e sociais diferentes e de adaptação. \\
Estão em destaque competências de comunicação, negociação, \\
mobilização para mudança, sensibilidade cultural, trabalhos em equipe, \\
flexibilidade e adaptabilidade, habilidade de desenvolver e transferir \\
conhecimento entre fronteiras.
\end{tabular}

Tabela 1: Uppsala com foco nas competências (SALVADOR, PORTO e PESSOA, 2009)

As competências essenciais sinalizadas acima podem ser entendidas a partir de seis divisões interligadas. A competência de negócios busca explorar a atividade de inovação a partir das habilidades e conhecimento que a empresa é capaz de obter. A aprendizagem é valorizada em conjunto com o conhecimento e a propensão a continuar aprendendo. O gradualismo de Uppsala reforça a forma como este conhecimento ocorre, sempre, de forma dinâmica. Para que o processo ocorra de forma satisfatória, é necessário que as empresas estejam cultural e internamente dispostas a investir em sua internacionalização.

A distância psíquica se relaciona às competências sociais a fim de minimizar as diferenças entre os mercados e permitir a interação e troca de interesses que são relevantes para as empresas quando em mercados estrangeiros. Por fim, a visão comportamental do modelo é representada pelas competências atitudinais, ou seja, as atitudes, percepções e comportamento dos tomadores de decisão. (SALVADOR, PORTO e PESSOA, 2009)

\section{Considerações Finais}

O presente artigo se propôs a uma revisão teórica à luz do modelo de Uppsala e da RBV, com o objetivo de explorar possíveis encontros e potencialidades entre as duas abordagens que enriqueçam discussões que se referem a processos de internacionalização das empresas.

Na leitura de Penrose (1966), o modelo de Uppsala possui a mesma vertente ontológica observada na RBV (inside-out). Da mesma forma, como postula a Visão Baseada em Recursos, a escola de Uppsala é de cunho racional e dependente das atitudes do gestor para sua implementação e para a evolução do processo de internacionalização em todas as suas etapas.

A ligação entre os modelos de internacionalização e as escolas estratégicas pode auxiliar a compreender as características do processo de formação da estratégia internacional das empresas. (OLIVEIRA et al., 2009).

Ao verificarem a quebra do modelo gradual de internacionalização, os autores de Uppsala revisitaram o modelo, a fim de considerar, por exemplo, a relevância do papel das redes de negócio (networks). Estas redes tendem a impactar na escolha do mercado de atuação das empresas e na forma como estas irão se inserir em determinado contexto. Desta forma, o relacionamento entre fornecedores, mercado e clientes aparece como um propulsor para a inserção das empresas em mercados globais. (SOARES, 2013). 
As redes de negócio permitem a troca entre os parceiros, o que conduz a um intercâmbio de conhecimentos que incluem recursos, capacidades, estratégias e relacionamentos decorrentes. Assim, estes parceiros irão se revelar valiosas fontes de informação comercial. (JOHANSON e VAHLNE, 2009).

Ao utilizar a abordagem da visão baseada em recursos a fim de entender a internacionalização de empresas em cadeias globais, percebe-se que o compartilhamento de recursos pode facilitar o próprio gerenciamento da rede. Os recursos tangíveis como, por exemplo, os financeiros, a localização e a tecnologia e os intangíveis (como a confiança), precisam ser compartilhados pelos participantes da rede para que estes obtenham vantagem competitiva. (LEITE, 2014).

Grande parte das teorias de internacionalização, em especial as que se dedicam aos estudos de empresas que se internacionalizam através de investimentos diretos, não são aplicáveis às empresas "Born Global". O modelo de Uppsala, combinado à abordagem da RBV, representa uma oportunidade profícua para o entendimento dos processos de internacionalização destas empresas. (REYNOSO e FIGUEROA, 2010).

Ao longo do tempo, o modelo de Uppsala foi analisado com base em características distintas, como o gradualismo e a aprendizagem. O reconhecimento do papel fundamental dos recursos e capacidades para a obtenção e manutenção de vantagem competitiva, que remete à RBV, possibilita um novo entendimento do processo de internacionalização, onde o desenvolvimento de recursos e capacidades organizacionais passa a ser determinante no processo de aprendizagem e obtenção de conhecimento sobre os mercados estrangeiros.

Entende-se que os modelos comportamentais de internacionalização tendem a exigir maiores competências, pois buscam reduzir incertezas, fruto de processos de aprendizagem. Ao observar o modelo de Uppsala, verifica-se que suas motivações estão intimamente relacionadas a questões de conhecimento e aprendizagem que exigirão, das empresas, competências delimitadas, como competências de negócio, técnico profissionais e atitudinais. (SALVADOR, PORTO e PESSOA, 2009).

A noção de distância psíquica, presente no modelo de Uppsala, pode ser reinterpretada quando as empresas estão organizadas em rede. Neste caso, o conhecimento de mercado é dificultado quando se está fora desta rede, e as diferenças culturais tendem a perder importância. Assim, o processo de internacionalização e a maneira como as empresas irão se posicionar no mercado dependerá estritamente dos relacionamentos observáveis na rede de negócio, assim como da confiança e conhecimento decorrentes. (CARVALHO e DIB, 2013).

Diante destas interpretações, sugere-se integrar os estudos de Uppsala à abordagem da Visão Baseada em Recursos, a fim de propiciar um melhor entendimento, por exemplo: do papel dos relacionamentos dentro das redes de negócios no desenvolvimento de recursos e capacidades que possibilitem o aprendizado e a geração de conhecimento e da importância da capacidade empreendedora para o reconhecimento de oportunidades e para a geração de conhecimento que possibilitem a internacionalização das firmas.

Outras oportunidades de discussão dizem respeito a investigações que contemplem os processos de internacionalização de empresas que atuam em mercados locais ou empresas "Born Global" a partir da visão estratégica da RBV e do modelo incremental de Uppsala. Ainda, o papel das instituições e dos aspectos culturais como impulsionadores da alocação de recursos em processos de internacionalização poderia ser explorado em estudos futuros.

Evidentemente, as reflexões aqui apresentadas representam uma contribuição cujo maior objetivo é o de fomentar o interesse e futuro debate em estudos de internacionalização e estratégia, tanto em termos de seus aspectos gerais quanto particulares. 


\section{Referências}

ANDERSEN, Otto. On the internationalization process of firms: a critical analysis. Journal of international business studies, p. 209-231, 1993.

BARNEY, Jay B. Strategic factor markets: Expectations, luck, and business strategy. Management science, v. 32, n. 10, p. 1231-1241, 1986.

BARNEY, Jay. Firm resources and sustained competitive advantage. Journal of management, V. 17, n. 1, p. 99-120, 1991.

DIB, Luis Antonio; CARNEIRO, Jorge. Avaliação comparativa do escopo descritivo e explanatório dos principais modelos de internacionalização de empresas. Anais do XXX ENANPAD. Salvador: ANPAD, 2006.

CARVALHO, Carlos Augusto Septímio de; DIB, Luis Antônio da Rocha. RECONCILIANDO O MODELO DE UPPSALA COM A PERSPECTIVA DE NETWORKS: REVISÃO CRÍTICA E INTEGRATIVA. Revista de Administração FACES Journal, v. 12, n. 2, 2013.

CHIAVEGATTI, Debora; TUROLLA, Frederico Araujo. Risco no Modelo de Internacionalização de Uppsala. Revista Organizações em Contexto-online, v. 7, n. 13, p. 129$156,2011$.

COLLIS, David J. Research note: how valuable are organizational capabilities?. Strategic management journal, v. 15, n. S1, p. 143-152, 1994.

ERIKSSON, Kent et al. Experiential knowledge and cost in the internationalization process. Journal of international business studies, v. 28, p. 337-360, 1997.

FLORIANI, Dinorá Elite; FLEURY, Maria Tereza. O efeito do grau de internacionalização nas competências internacionais e no desempenho financeiro da PME Brasileira. Revista de Administração Contemporânea, v. 16, n. 3, p. 438-458, 2012.

GÓES, B. B., \& ROCHA, A. (2007, maio). A Lógica Geoestratégica da Expansão Empresarial: Estudo de Caso de uma Empresa Brasileira. Anais do Encontro De Estudos Em Estratégia. São Paulo. São Paulo, Brasil, 3.

HILAL, Adriana; HEMAIS, Carlos A. O processo de internacionalização na ótica da escola nórdica: evidências empíricas em empresas brasileiras. Revista de Administração Contemporânea, v. 7, n. 1, p. 109-124, 2003.

JARILLO, J.; MARTINEZ, J. The international expansion of Spanish firms: towards an integrative framework for international strategy. Corporate and industry strategies for Europe, p. 283-302, 1991.

JOHANSON, Jan; VAHLNE, Jan-Erik. The internationalization process of the firm-a model of knowledge development and increasing foreign market commitments. Journal of international business studies, v. 8, n. 1, p. 23-32, 1977.

JOHANSON, Jan; VAHLNE, Jan-Erik. The Uppsala internationalization process model revisited: From liability of foreignness to liability of outsidership. Journal of international business studies, v. 40, n. 9, p. 1411-1431, 2009. 
JOHANSON, Jan; WIEDERSHEIM-PAUL, Finn. The internationalization of the firm-four swedish cases 1. Journal of management studies, v. 12, n. 3, p. 305-323, 1975.

LEI, Han-Sheng; CHEN, Yung-Shuan. The right tree for the right bird: Location choice decision of Taiwanese firms' FDI in China and Vietnam. International Business Review, v. 20, n. 3, p. 338-352, 2011.

LEITE, Yákara Vasconcelos Pereira; PRIMO, Marcos André Mendes. Cadeias globais: uma contribuição da RBV no processo de internacionalização. Produto \& Produção, v. 15, n. 1, p. 10-21, 2014.

PHILliPS MCDOUGALL, Patricia; SHANE, Scott; OVIATT, Benjamin M. Explaining the formation of international new ventures: The limits of theories from international business research. Journalof business venturing, v. 9, n. 6, p. 469-487, 1994.

MAZON, Fernando Sergio; DA SILVA, Wesley Vieira. Internacionalização De Pequenos E Médios Empreendimentos: Benefícios Para A Gestão $E$ Geração De Conhecimento. SIMPOI-Simpósio de Administração da Produção, Logística e Operações Internacionais, 2009

MELIN, Leif. Internationalization as a strategy process. Strategic Management Journal, v. 13, n. S2, p. 99-118, 1992.

MILLINGTON, Andrew I.; BAYLISS, Brian T. The process of internationalisation: UK companies in the EC. MIR: Management International Review, p. 151-161, 1990.

OLIVEIRA, Brigitte Renata B. et al. Processo de formação de estratégias internacionais na fruticultura brasileira: uma abordagem integrada. Cadernos Ebape, v. 7, n. 2, p. 295-313, 2009.

PENG, Mike W. The resource-based view and international business.Journal of Management, v. 27, n. 6, p. 803-829, 2001.

PENROSE, Edith Tilton. The Theory of the Growth of the Firm. Oxford University Press, 1996

PETERAF, Margaret A. The cornerstones of competitive advantage: A resource-based view. Strategic management journal, v. 14, n. 3, p. 179-191, 1993.

PRAHALAD, C. K.; HAMEL, Gary. The core competence of the corporation.Boston (MA), p. 235-256, 1990.

REYNOSO, Carlos Fong; FIGUEROA, Luis Ernesto O campo. Intangible resources as a determinant of accelerated internationalization. Global Journal of Business Research-GJBR, v. 4, n. 4, p. 95-105, 2010.

ROCHA, A. da; ALMEIDA, Victor. Estratégias de entrada e de operação em mercados internacionais. TANURE, B.; DUARTE, RG Gestão internacional. São Paulo: Saraiva, 2006.

SALAZAR, Viviane Santos et al. Resourced based view: Das proposições de Penrose à Internacionalização. RAUnP-ISSN 1984-4204, v. 5, n. 1, p. 71-80, 2012. 
SALVADOR, Regina Lúcia de Carvalho Drummond; PORTO, Lana; PESSOA, Fabiana Lana. ANÁLISE DO MODELO DE UPPSALA COM FOCO NAS COMPETÊNCIAS REQUERIDAS PARA SUA OPERACIONALIZAÇÃO. Gestão e Sociedade, v. 2, n. 3, 2009.

SHARMA, Varinder M.; ERRAMILLI, M. Krishna. Resource-based explanation of entry mode choice. Journalof Marketing Theory and Practice, p. 1-18, 2004.

SCHWEIZER, Roger; VAHLNE, Jan-Erik; JOHANSON, Jan. Internationalization as an entrepreneurial process. Journal of International Entrepreneurship, v. 8, n. 4, p. 343-370, 2010.

TEECE, David J.; PISANO, Gary; SHUEN, Amy. Dynamic capabilities and strategic management. 1997.

TREVINO, Len J.; GROSSE, Robert. An analysis of firm-specific resources and foreign direct investment in the United States. International Business Review, v. 11, n. 4, p. 431-452, 2002.

WERNERFELT, Birger. A resource-based view of the firm. Strategic management journal, v. 5, n. 2, p. 171-180, 1984.

WESTHEAD, Paul; WRIGHT, Mike; UCBASARAN, Deniz. The internationalization of new and small firms: A resource-based view. Journal of business venturing, v. 16, n. 4, p. 333-358, 2001.

WHITELOCK, Jeryl. Theories of internationalisation and their impact on market entry. International marketing review, v. 19, n. 4, p. 342-347, 2002.

WINTER, Sidney G.; NELSON, Richard R. An evolutionary theory of economic change. University of Illinois at Urbana-Champaign's Academy for Entrepreneurial Leadership Historical Research Reference in Entrepreneurship, 1982. 